\title{
High Disease Activity May Increase Fear-Avoidance Beliefs in Rheumatoid Arthritis
}

\author{
Mehmet Engin TEZCAN, ${ }^{1}$ Berfu CINKİT DOĞAN, ${ }^{2}$ Nesrin ŞEN, ${ }^{1}$ Mehmet SARGIN ${ }^{2}$ \\ ${ }^{1}$ Department of Rheumatology, Kartal Dr. Lütfi Kırdar Training and Research Hospital, Istanbul, Turkey \\ ${ }^{2}$ Department of Family Medicine and Diabetes, Kartal Dr. Lütfi Kırdar Training and Research Hospital, İstanbul, Turkey
}

\begin{abstract}
Objectives: This study aims to compare fear-avoidance (FA) beliefs of rheumatoid arthritis (RA) patients with osteoarthritis (OA) of hand patients and fibromyalgia (FM) patients and evaluate its relationship with RA activity and duration.

Patients and methods: The study included 206 patients with RA (34 males, 172 females; mean age 49 years; range 20 to 72 years), 57 patients with FM (57 females; mean age 48 years; range 20 to 71 years), and 50 patients with OA of hand (4 males, 46 females; mean age 43 years; range 43 to 77 years). FA beliefs were assessed with modified Fear-Avoidance Belief Questionnaire (mFABQ). RA patients were dichotomized according to disease activity and disease duration separately; cutoff values were disease activity score 28 of 3.2 and six months of disease activity, respectively.

Results: Modified Fear-Avoidance Belief Questionnaire scores were similar in patients with RA, OA of hand, and FM. RA patients in non-remission group had higher mFABQ scores. Moreover, mFABQ scores were similar in RA patients with early and established disease groups.

Conclusion: Fear-avoidance beliefs of patients with RA were similar with OA of hand patients and FM patients. However, higher disease activity in RA was related with escalated FA beliefs. Further studies focusing on pathophysiology of FA beliefs in patients with RA are warranted for effective pain management of RA.

Keywords: Disease activity; fear-avoidance beliefs; fibromyalgia; osteoarthritis; rheumatoid arthritis.
\end{abstract}

Fear-avoidance (FA) beliefs are significantly associated with the experience of pain. ${ }^{1}$ These beliefs are thought to be related with the development of chronic pain syndrome in some individuals with musculoskeletal pain. ${ }^{2}$ As fear and anxiety were found to be natural responses to impending pain, a FA model of exaggerated pain perceptions was postulated which depends on cognitive-behavioral accounts. ${ }^{3}$ Briefly, fear and anxiety generated by cognitively exaggerated pain sensation may influence the behaviors of people. For instance, in patients with low-back pain, FA beliefs may preclude return to work related with reduced physical activity. 4

Rheumatoid arthritis (RA) is one of the most common chronic inflammatory joint diseases, mainly characterized by chronic inflammatory pain in peripheral small joints. ${ }^{6}$ FA beliefs of patients with RA might be a factor for workforce loss and reduced physical activity.

Limited number of studies have been conducted that evaluated FA beliefs in patients with rheumatic diseases. Lööf et al. ${ }^{5}$ evaluated the FA beliefs about physical activity in adults with RA as a part of Physical Activity in Rheumatoid Arthritis 2010 study. Male sex, below average income, high level of pain, poor health and low health quality scores were found related with FA beliefs in RA. Also, Sánchez-Herán et al. ${ }^{7}$ found that FA beliefs negatively affect the postural stability in osteoarthritis (OA) of hip and knee.

Fear-avoidance beliefs were also evaluated in patients with first time myocardial infarction, ${ }^{8}$ leg 
ulcers, ${ }^{9}$ and other musculoskeletal pain syndromes apart from low-back pain. ${ }^{10,11}$

In this study, we aimed to compare FA beliefs of RA patients with OA of hand patients and FM patients and evaluate its relationship with RA activity and duration.

\section{PATIENTS AND METHODS}

The study, which was conducted at Kartal Dr. Lütfi Kurdar Training and Research Hospital between November 2015 and February 2016, included 206 patients with RA (34 males, 172 females; mean age 49 years; range 20 to 72 years) who fulfilled the 2010 American College of Rheumatology (ACR)/European League Against Rheumatism RA Classification Criteria, ${ }^{12} 57$ patients with FM (57 females; mean age 48 years; range 20 to 71 years) who fulfilled the 2010 ACR Preliminary Diagnostic Criteria for $\mathrm{FM},{ }^{13}$ and 50 patients with OA of hand (4 males, 46 females; mean age 43 years; range 43 to 77 years) who fulfilled the 1990 ACR Classification Criteria for OA of Hands. ${ }^{14}$ FA beliefs were measured by The Fear-Avoidance Belief Questionnaire (FABQ), originally described by Waddell et al. ${ }^{15}$ The questionnaire has two components including FA beliefs about work and physical activity. Main determinants of the scale are pain related fear and pain severity. The FABQ is accepted as one of the best available instrument to measure fear and avoidance behavior related with physical activity and work. ${ }^{16}$ In our study, we measured FA beliefs with modified version of The FearAvoidance Belief Questionnaire (mFABQ). ${ }^{17}$ In the modified version of the questionnaire, two items which evaluate only back pain were excluded. The questionnaire includes four items on FA beliefs about physical activity and 10 items on FA beliefs about work. Here, all items were rated on a seven point scale (0-6). The validity and reliability of the questionnaire have been reported in patients with chronic musculoskeletal pain $^{17}$ and the Turkish version of mFABQ was previously validated. ${ }^{18}$ Three different scores were obtained from the questionnaire: $\mathrm{mFABQ}$ physical activity score was derived from the ratings of four items on FA beliefs about physical activity. $\mathrm{mFABQ}$ work score was derived from the ratings of 10 items on FA beliefs about work. Finally, mFABQ total score was sum of these two scores. All scores dichotomized as low (mFABQ physical activity score [0-6], mFABQ work score [0-12] and mFABQ total score [0-18]) or high (mFABQ physical activity score [7-24], mFABQ work score [13-60] and mFABQ total score [19-84]) according to medians of a previous study. ${ }^{19}$ All patients were literate and none of the patients had pathological finding in the examinations that may influence the questionnaire. Demographic features, duration of education, smoking habits, occupation, body mass index, visual analog scores of pain, fatigue and patients global health, duration of disease related symptoms, comorbid illnesses (hypertension, hypothyroidism, hyperthyroidism, cardiovascular diseases, coronary artery diseases, cerebrovascular diseases, chronic renal disease, chronic obstructive pulmonary disease, diabetes mellitus), and number of lost days being unable to work due to pain during last month were collected from all patients. Counts of tender and swollen joints of the patients with RA were detected with physical examination by the same rheumatologist. C-reactive protein and sedimentation rates of all patients and rheumatoid factor and anti-citrullinated protein antibodies of the patients with RA were obtained from the medical database of the hospital. Treatments for RA at the time of study were also obtained. Drug treatments for RA were classified as no treatment, monotherapy with methotrexate, monotherapy with other disease modifying drugs (DMARDs) (hydroxychloroquine, leflunomide, sulfasalazine), DMARD combination including methotrexate, DMARD combination without methotrexate, biologic monotherapy with tumor necrosis factor inhibitors (TNFi) (adalimumab, certolizumab pegol, etanercept, golimumab, or infliximab), biologic monotherapy with non-TNFi (abatacept, rituximab, or tocilizumab), biologic and DMARD combination including TNFi, biologic and DMARD combination including non-TNFi. Corticosteroid treatment for RA was classified into three subclasses according to dosage: no steroid treatment, treatment with prednisolone equivalent $<5 \mathrm{mg}, 5-10 \mathrm{mg}$ and $>10 \mathrm{mg}$ daily. The activity of RA was evaluated with disease activity score 28 with sedimentation rate. ${ }^{20}$ Disease activity score 28 was classified as remission, low, moderate and high disease 
activity according to ACR/European League Against Rheumatism provisional definition of remission in RA for clinical trials. ${ }^{21}$ RA patients were divided into two groups related to remission status. Herein, disease activity score 28 of 3.2 was accepted as cutoff value. Remission group involved patients with remission and low disease activity. Additionally, non-remission group involved patients with moderate and high disease activity. Furthermore, patients with RA were divided into two groups according to disease duration. In compliance with 2015 ACR Guidelines for the Treatment of RA, cutoff value of disease duration for separating the patients as early or established RA was accepted as six months. ${ }^{22}$ Occupation of the patients was classified according to exertion levels as outlined in the Standards of United States Department of Labor as defined in the Dictionary of Occupational Titles. ${ }^{23}$

The study protocol was approved by the Kartal Dr. Lütfi Kırdar Training and Research Hospital Ethics Committee. A written informed consent was obtained from each patient. The study was conducted in accordance with the principles of the Declaration of Helsinki.

\section{Statistical analysis}

Statistical analyses were carried out using PASW version 17.0 (SPSS Inc., Chicago, IL, USA). In order to determine if the data were normally distributed, the Kolmogorov-Smirnov test was performed. Comparison of the continuous variables between patients with RA, OA and FM were performed by analysis of variance and/or Kruskal-Wallis test depending on the normality of the distribution. Then, if a significant difference was found between groups, Student's t-test and/or Mann-Whitney U test with Bonferroni correction were performed for evaluating difference between groups. Comparison of the continuous variables between two groups, if necessary, was performed by Student's t-test and/or Mann-Whitney $U$ test depending on the normality of the distribution. Comparisons of the categorical variables were performed by using Chi-square test and Bonferroni correction was performed for evaluating the difference between groups. Results are given as mean \pm standard deviation or median (interquartile range) according to distribution and a $p$ value lower than 0.05 was considered as statistically significant.

\section{RESULTS}

Frequency of male sex in the RA group was higher than patients in FM group $(p=0.002)$. Patients in OA of hand group were older than both RA and FM groups (both $\mathrm{p}<0.001$ ). RA group had more sedentary occupations than FM group $(p=0.02)$. OA of hand group had more comorbid illnesses than RA group $(p<0.001)$. Other descriptive properties were similar in all study groups (Table 1).

C-reactive protein levels of RA group were significantly higher than FM group $(p=0.03)$. Three of the visual analog scale (VAS) scores were significantly higher in FM group (both $p<0.001$ ). VAS scores were similar in RA and OA of hand groups. mFABQ work, mFABQ physical activity, and $\mathrm{mFABQ}$ total scores were similar in all study groups (Table 1).

Demographic properties were similar in the remission and the non-remission groups (Table 2). Also, frequency of rheumatoid factor and anticitrullinated protein antibodies positivity were similar in both groups.

More patients in non-remission group had early disease $(p<0.001)$. However, in both groups, most of the patients had established disease. VAS scores were higher in non-remission group (all $\mathrm{p}<0.001$ ). Sedimentation rates and C-reactive protein values were also higher in non-remission group. Moreover, number of lost days being unable to work due to pain during last month was higher in non-remission group. Non-remission group was on higher corticosteroid dosage in the course of the study. Furthermore, non-remission group had higher number of tender and swollen joints (both $\mathrm{p}<0.001$ ). Modified Fear-Avoidance Belief Questionnaire total $(p<0.001)$, mFABQ physical activity $(\mathrm{p}<0.001)$ and $\mathrm{mFABQ}$ work $(p=0.009)$ scores were higher in non-remission group (Table 2).

Frequency of male sex was higher in early disease group $(p=0.004)$. Other demographic properties were similar. Seropositivity was higher in established disease group $(p=0.02)$ (Table 3).

Majority of the patients in early disease group had active disease, conversely, more than half of the patients with established disease were in 


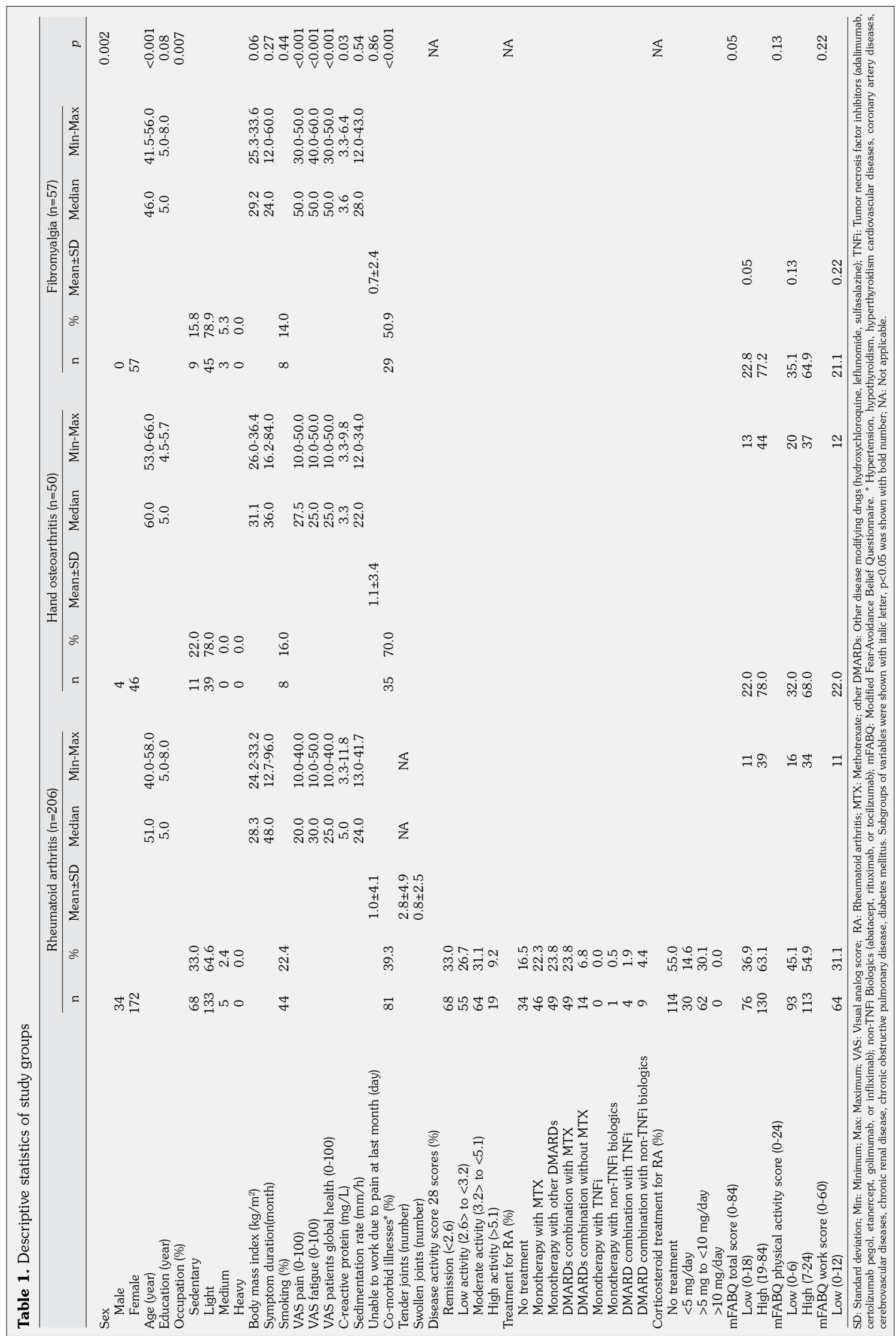




\begin{tabular}{|c|c|c|c|c|c|c|c|c|c|c|c|}
\hline & \multicolumn{5}{|c|}{ Remission $(\mathrm{n}=123)$} & \multicolumn{5}{|c|}{ Non-remission $(\mathrm{n}=83)$} & \multirow[b]{2}{*}{$p$} \\
\hline & $\mathrm{n}$ & $\%$ & Mean \pm SD & Median & Min-Max & $\mathrm{n}$ & $\%$ & Mean \pm SD & Median & Min-Max & \\
\hline Sex & & & & & & & & & & & 0.78 \\
\hline Male & 21 & & & & & 13 & & & & & \\
\hline Female & 102 & & & & & 70 & & & & & \\
\hline Age (year) & & & & 51.0 & $40.0-58.0$ & & & & 50.0 & $41.0-59.0$ & 0.95 \\
\hline Education (year) & & & & 5.0 & $5.0-8.0$ & & & & 5.0 & $5.0-8.0$ & 0.27 \\
\hline Occupation (\%) & & & & & & & & & & & 0.44 \\
\hline Sedentary & 45 & 36.6 & & & & 23 & 27.7 & & & & \\
\hline Light & 75 & 61.0 & & & & 58 & 69.9 & & & & \\
\hline Medium & 3 & 2.4 & & & & 2 & 2.4 & & & & \\
\hline Heavy & 0 & 0.0 & & & & 0 & 0.0 & & & & \\
\hline Body mass index $\left(\mathrm{kg} / \mathrm{m}^{2}\right)$ & & & & 28.0 & $24.0-33.0$ & & & & 29.0 & $25.6-33.2$ & 0.26 \\
\hline Disease duration & & & & & & & & & & & $<0.001$ \\
\hline Early (\%) & 10 & 8.1 & & & & 23 & 27.7 & & & & \\
\hline Established (\%) & 113 & 91.9 & & & & 60 & 72.3 & & & & \\
\hline Smoking (\%) & 28 & 22.8 & & & & 16 & 19.3 & & & & 0.54 \\
\hline VAS pain $(0-100)$ & & & & 10.0 & $10.0-20.0$ & & & & 40.0 & $30.0-50.0$ & $<0.001$ \\
\hline VAS fatigue $(0-100)$ & & & & 20.0 & $10.0-40.0$ & & & & 40.0 & $30.0-50.0$ & $<0.001$ \\
\hline VAS patients global health $(0-100)$ & & & & 10.0 & $10.0-25.0$ & & & & 40.0 & $30.0-50.0$ & $<0.001$ \\
\hline C-reactive protein $(\mathrm{mg} / \mathrm{L})$ & & & & 3.8 & 3.3-7.9 & & & & 9.4 & $3.3-18.2$ & $<0.001$ \\
\hline Sedimentation rate $(\mathrm{mm} / \mathrm{h})$ & & & & 19.5 & $11.2-34.0$ & & & & 34.0 & $20.2-48.0$ & $<0.001$ \\
\hline Rheumatoid factor positivity (\%) & $47 / 108$ & 43.5 & & & & $30 / 77$ & 39.0 & & & & 0.53 \\
\hline ACPA positivity (\%) & $25 / 65$ & 38.5 & & & & $20 / 50$ & 40.0 & & & & 0.86 \\
\hline Unable to work due to pain at last month (day) & & & $0.2 \pm 0.7$ & & & & & $2.3 \pm 6.2$ & & & 0.001 \\
\hline Co-morbid illnesses* $(\%)$ & 46 & 37.4 & & & & 35 & 42.2 & & & & 0.44 \\
\hline Tender joints (number) & & & $0.2 \pm 0.7$ & & & & & $6.50 \pm 6.0$ & & & $<0.001$ \\
\hline Swollen joints (number) & & & $0.1 \pm 0.3$ & & & & & $1.9 \pm 3.7$ & & & $<0.001$ \\
\hline Treatment for RA (\%) & & & & & & & & & & & \\
\hline No treatment & 7 & 5.7 & & & & 27 & 32.5 & & & & \\
\hline Monotherapy with MTX & 30 & 24.4 & & & & 16 & 19.3 & & & & \\
\hline Monotherapy with other DMARDs & 40 & 32.5 & & & & 9 & 10.8 & & & & \\
\hline DMARDs combination with MTX & 33 & 26.8 & & & & 16 & 19.3 & & & & \\
\hline DMARDs combination without MTX & 5 & 4.1 & & & & 9 & 10.8 & & & & \\
\hline Monotherapy with TNFi & 0 & 0.0 & & & & 0 & 0.0 & & & & \\
\hline Monotherapy with non-TNFi biologics & 1 & 0.8 & & & & 0 & 0.0 & & & & \\
\hline DMARD combination with TNFi & 2 & 1.6 & & & & 2 & 2.4 & & & & \\
\hline DMARD combination with non-TNFi biologics & 5 & 4.1 & & & & 4 & 4.8 & & & & \\
\hline Corticosteroid treatment for RA (\%) & & & & & & & & & & & 0.02 \\
\hline No treatment & 70 & 56.9 & & & & 44 & 53.0 & & & & \\
\hline$<5 \mathrm{mg} /$ day & 25 & 20.3 & & & & 5 & 6.0 & & & & \\
\hline$>5 \mathrm{mg}$ to $<10 \mathrm{mg} /$ day & 28 & 22.3 & & & & 34 & 41.0 & & & & \\
\hline$>10 \mathrm{mg} /$ day & 0 & 0.0 & & & & 0 & 0.0 & & & & \\
\hline mFABQ total score $(0-84)$ & & & & & & & & & & & $<0.001$ \\
\hline Low $(0-18)$ & 62 & 50.4 & & & & 14 & 16.9 & & & & \\
\hline High (19-84) & 61 & 49.6 & & & & 69 & 83.1 & & & & \\
\hline mFABQ physical activity score $(0-24)$ & & & & & & & & & & & $<0.001$ \\
\hline Low $(0-6)$ & 72 & 58.5 & & & & 21 & 25.3 & & & & \\
\hline High (7-24) & 51 & 41.5 & & & & 62 & 74.7 & & & & \\
\hline mFABQ work score $(0-60)$ & & & & & & & & & & & 0.009 \\
\hline Low $(0-12)$ & 47 & 38.2 & & & & 7 & 20.5 & & & & \\
\hline High (13-60) & 76 & 61.8 & & & & 66 & 79.5 & & & & \\
\hline
\end{tabular}

remission $(p<0.001)$. Only VAS pain score was higher in early disease group $(p=0.001)$. Both VAS fatigue and VAS patients' global health scores were similar in early disease and established disease groups. Furthermore, number of tender joints $(p<0.001)$, swollen joints $(p<0.001)$ and lost days being unable to work due to pain during last month $(p=0.004)$ were higher in early disease group (Table 3).

Modified Fear-Avoidance Belief Questionnaire work, mFABQ physical activity and mFABQ total scores were similar in both early disease and established disease groups (Table 3).

\section{DISCUSSION}

In this study, we compared FA beliefs in RA patients with OA of hand patients and FM patients and evaluated the impact of disease activity and duration of RA on FA beliefs. Our findings revealed no difference in FA beliefs between RA, OA of hand and FM groups. Moreover, we found that FA beliefs of the active RA patients were higher compared to patients with low disease activity.

To the best of our knowledge, no studies have been conducted in the English literature that compared FA beliefs of different diseases. We compared FA beliefs of RA patients with 


\begin{tabular}{|c|c|c|c|c|c|c|c|c|c|c|c|}
\hline & \multicolumn{5}{|c|}{ Early RA $(\mathrm{n}=33)$} & \multicolumn{5}{|c|}{ Established RA ( $\mathrm{n}=173$ ) } & \multirow[b]{2}{*}{$p$} \\
\hline & $\mathrm{n}$ & $\%$ & Mean \pm SD & Median & Min-Max & $\mathrm{n}$ & $\%$ & Mean \pm SD & Median & Min-Max & \\
\hline Sex & & & & & & & & & & & 0.004 \\
\hline Female & 11 & & & & & 23 & & & & & \\
\hline Male & 22 & & & & & 150 & & & & & \\
\hline Age (year) & & & & 51.0 & $37.5-59.5$ & & & & 51.0 & $40.5-58.0$ & 0.78 \\
\hline Education (year) & & & & 5.0 & $5.0-12.0$ & & & & 5.0 & $5.0-8.0$ & 0.93 \\
\hline Occupation (\%) & & & & & & & & & & & 0.18 \\
\hline Sedentary & 15 & 45.5 & & & & 53 & 30.6 & & & & \\
\hline Light & 18 & 54.5 & & & & 115 & 66.5 & & & & \\
\hline Medium & 0 & 0.0 & & & & 5 & 2.9 & & & & \\
\hline Heavy & 0 & 0.0 & & & & 0 & 0.0 & & & & \\
\hline Body mass index $\left(\mathrm{kg} / \mathrm{m}^{2}\right)$ & & & & 29.4 & $25.8-33.2$ & & & & 28.1 & $24.0-33.2$ & 0.42 \\
\hline Smoking (\%) & 4 & 12.1 & & & & 40 & 23.1 & & & & 0.15 \\
\hline VAS pain $(0-100)$ & & & & 35.0 & $30.0-50.0$ & & & & 20.0 & $10.0-30.0$ & 0.001 \\
\hline VAS fatigue $(0-100)$ & & & & 30.0 & $10.0-50.0$ & & & & 30.0 & $10.0-50.0$ & 0.62 \\
\hline VAS patients global health $(0-100)$ & & & & 30.0 & $20.0-50.0$ & & & & 20.0 & $10.0-30.0$ & 0.12 \\
\hline C-reactive protein $(\mathrm{mg} / \mathrm{L})$ & & & & 7.2 & $3.3-12.1$ & & & & 4.7 & 3.3-11.7 & 0.42 \\
\hline Sedimentation rate $(\mathrm{mm} / \mathrm{h})$ & & & & 21.0 & $12.0-38.0$ & & & & 24.0 & $13.0-42.0$ & 0.61 \\
\hline Rheumatoid factor positivity (\%) & $7 / 30$ & 23.3 & & & & $70 / 155$ & 45.2 & & & & 0.02 \\
\hline ACPA positivity (\%) & $8 / 21$ & 38.1 & & & & $37 / 94$ & 39.4 & & & & 0.91 \\
\hline Unable to work due to pain at last month (day) & & & $2.8 \pm 6.1$ & & & & & $0.7 \pm 3.5$ & & & 0.004 \\
\hline Co-morbid illnesses* $(\%)$ & 15 & 45.5 & & & & 67 & 38.8 & & & & 0.44 \\
\hline Tender joints (number) & & & $5.3 \pm 6.2$ & & & & & $2.3 \pm 4.5$ & & & $<0.001$ \\
\hline Swollen joints (number) & & & $2.7 \pm 4.9$ & & & & & $0.4 \pm 1.5$ & & & $<0.001$ \\
\hline Disease activity score 28 scores (\%) & & & & & & & & & & & $<0.001$ \\
\hline Remission $(<2.6)$ & 10 & 30.3 & & & & 113 & 65.3 & & & & \\
\hline Non-remission $(>2.6)$ & 23 & 69.7 & & & & 60 & 34.7 & & & & \\
\hline Treatment for RA (\%) & & & & & & & & & & & \\
\hline No treatment & 19 & 57.6 & & & & 15 & 8.7 & & & & \\
\hline Monotherapy with MTX & 11 & 33.3 & & & & 35 & 20.2 & & & & \\
\hline Monotherapy with other DMARDs & 1 & 3.0 & & & & 48 & 27.7 & & & & \\
\hline DMARDs combination with MTX & 2 & 6.1 & & & & 47 & 27.2 & & & & \\
\hline DMARDs combination without MTX & 0 & 0.0 & & & & 14 & 8.1 & & & & \\
\hline Monotherapy with TNFi & 0 & 0.0 & & & & 0 & 0.0 & & & & \\
\hline Monotherapy with non-TNFi biologics & 0 & 0.0 & & & & 1 & 0.6 & & & & \\
\hline DMARD combination with TNFi & 0 & 0.0 & & & & 4 & 2.3 & & & & \\
\hline DMARD combination with non-TNFi biologics & 0 & 0.0 & & & & 9 & 5.2 & & & & \\
\hline Corticosteroid treatment for RA (\%) & & & & & & & & & & & 0.17 \\
\hline No treatment & 23 & 69.7 & & & & 91 & 52.6 & & & & \\
\hline$<5 \mathrm{mg} /$ day & 4 & 12.1 & & & & 26 & 15.0 & & & & \\
\hline$>5 \mathrm{mg}$ to $<10 \mathrm{mg} /$ day & 6 & 18.2 & & & & 56 & 32.4 & & & & \\
\hline$>10 \mathrm{mg} / \mathrm{day}$ & 0 & 0.0 & & & & 0 & 0.0 & & & & \\
\hline mFABQ total score $(0-84)$ & & & & & & & & & & & 0.41 \\
\hline Low $(0-18)$ & 10 & 30.3 & & & & 66 & 38.2 & & & & \\
\hline High (19-84) & 23 & 69.7 & & & & 107 & 61.8 & & & & \\
\hline mFABQ physical activity score $(0-24)$ & & & & & & & & & & & 0.26 \\
\hline Low (0-6) & 12 & 36.4 & & & & 81 & 46.8 & & & & \\
\hline High (7-24) & 21 & 63.6 & & & & 92 & 53.2 & & & & \\
\hline mFABQ work score $(0-60)$ & & & & & & & & & & & 0.37 \\
\hline Low $(0-12)$ & 8 & 24.2 & & & & 67 & 38.8 & & & & \\
\hline High (13-60) & 25 & 75.8 & & & & 106 & 61.2 & & & & \\
\hline
\end{tabular}

patients of two different diseases. Although RA is an articular and inflammatory disease,$^{24} \mathrm{mFABQ}$ scores of RA patients were not different from patients with OA of hand or FM. Furthermore, higher VAS scores in FM patients might not constitute a difference in FA beliefs. Therefore, we might suggest that cognitive-behavioral accounts that may aggregate pain sensation and sensemaking of pain in cognitive level may influence FA beliefs rather than the characteristics of the diseases or intensity of pain. ${ }^{3}$ Limited number of studies evaluated FA beliefs of FM or OA patients. In the first study of Palstam et al., ${ }^{25}$ it was found that elevated perceived exertion at work increased FA beliefs of patients with FM. Moreover, the second study of Palstam et al. ${ }^{26,27}$ considered FA beliefs as a treatment parameter. Furthermore, Sánchez-Herán et al. ${ }^{7}$ evaluated the relationship between FA beliefs and the postural stability in $\mathrm{OA}$ of hip and knee. Nevertheless, none of the studies compared the FA beliefs of FM or OA patients with other, particularly inflammatory diseases. Consequently, our study was the first study that compared the impact of FM and OA on FA beliefs with an inflammatory disease. In this study, FA beliefs were similar in three diseases.

We found higher $\mathrm{mFABQ}$ scores in nonremission RA group. Moreover; VAS scores, number of tender or swollen joints and number 
of lost days being unable to work due to pain during last month were higher in non-remission group. Increased pain intensity in active disease and escalating damage, suffering and functional loss beliefs due to increased number of tender or swollen joints may be the reason for underlying high pain-related fear. ${ }^{27}$ So, compatible with the literature, our findings showed that disease activity was related with escalating FA beliefs. Therefore, higher FA beliefs in non-remission RA patients may preclude return to work, related with reduced physical activity and chronic pain syndrome., ${ }^{1,28}$

Unlike the literature, our results did not show any association between disease chronicity and increased FA beliefs. ${ }^{3}$ In our study, there was no difference in $\mathrm{mFABQ}$ scores according to the disease duration of RA patients. The reason for this may be our established RA group's having lower disease activity. Thus, our findings may indicate that only disease chronicity in RA do not increase FA beliefs without high disease activity. Even though early disease group had higher disease activity, disease duration might not be sufficient to cause cognitive alterations for revealing FA beliefs.

As increased disease activity in RA was related with increased FA beliefs, increased work loss and decreased physical activity, intensive treatment with treat to target strategy ${ }^{29}$ may increase remission rate and help to combat against FA beliefs. Moreover, an inverse relationship was found between knowledge of pain neurophysiology and the level of FA. ${ }^{30}$ Consequently, pain education ${ }^{31}$ in patients with RA may provide an effective strategy to manage FA and related disability in RA patients, improving treatment outcomes. Furthermore, as FA beliefs originate from cognitive-behavior accounts, physician-patient communication that centralizes the impact of RA on quality of life ${ }^{32}$ and guides the treatment according to patients' expectations and perceptions ${ }^{33}$ may also help to combat against FA beliefs.

Our study has some limitations. Firstly, a limited number of patients with early diagnosed RA were enrolled. Secondly, we did not evaluate the effect of RA treatments on FA beliefs in RA. Also, we did not consider health quality indices. Furthermore, this was a cross-sectional study not designed to demonstrate the alterations of FA beliefs in the different stages of the disease.
Lastly, we did not evaluate FM in patients with $\mathrm{RA}$ and $\mathrm{OA}$.

In conclusion, FA beliefs of patients with RA were similar with OA of hand patients and FM patients. However, increased RA activity was related with increased FA beliefs, particularly in established disease. Thus, intensive treat to target strategy and patient-oriented treatment methods focused on cognitive-behavior accounts may help in combatting against FA beliefs of RA patients. Further studies evaluating the pathophysiology and treatment of FA beliefs of patients with RA are warranted for effective pain management in RA.

\section{Declaration of conflicting interests}

The authors declared no conflicts of interest with respect to the authorship and/or publication of this article.

\section{Funding}

The authors received no financial support for the research and/or authorship of this article.

\section{REFERENCES}

1. Gatchel RJ, Neblett R, Kishino N, Ray CT. FearAvoidance Beliefs and Chronic Pain. J Orthop Sports Phys Ther 2016;46:38-43.

2. Vlaeyen JW, Linton SJ. Fear-avoidance and its consequences in chronic musculoskeletal pain: a state of the art. Pain 2000;85:317-32.

3. Leeuw M, Goossens ME, Linton SJ, Crombez G, Boersma K, Vlaeyen JW. The fear-avoidance model of musculoskeletal pain: current state of scientific evidence. J Behav Med 2007;30:77-94.

4. Fritz JM, George SZ. Identifying psychosocial variables in patients with acute work-related low back pain: the importance of fear-avoidance beliefs. Phys Ther 2002;82:973-83.

5. Lööf H, Demmelmaier I, Henriksson EW, Lindblad S, Nordgren B, Opava $\mathrm{CH}$, et al. Fear-avoidance beliefs about physical activity in adults with rheumatoid arthritis. Scand J Rheumatol 2015;44:93-9.

6. Symmons DP. Epidemiology of rheumatoid arthritis: determinants of onset, persistence and outcome. Best Pract Res Clin Rheumatol 2002;16:707-22.

7. Sánchez-Herán Á, Agudo-Carmona D, Ferrer-Peña R, López-de-Uralde-Villanueva I, Gil-Martínez A, ParisAlemany A, et al. Postural Stability in Osteoarthritis of the Knee and Hip: Analysis of Association With Pain Catastrophizing and Fear-Avoidance Beliefs. PM R 2016;8:618-28. 
8. Åhlund K, Bäck M, Sernert N. Fear-avoidance beliefs and cardiac rehabilitation in patients with first-time myocardial infarction. J Rehabil Med 2013;45:1028-33.

9. Roaldsen KS, Elfving B, Stanghelle JK, Talme T, Mattsson E. Fear-avoidance beliefs and pain as predictors for low physical activity in patients with leg ulcer. Physiother Res Int 2009;14:167-80.

10. Sindhu BS, Lehman LA, Tarima S, Bishop MD, Hart DL, Klein MR, et al. Influence of fear-avoidance beliefs on functional status outcomes for people with musculoskeletal conditions of the shoulder. Phys Ther 2012;92:992-1005.

11. Inrig T, Amey B, Borthwick C, Beaton D. Validity and reliability of the Fear-Avoidance Beliefs Questionnaire (FABQ) in workers with upper extremity injuries. J Occup Rehabil 2012;22:59-70.

12. Aletaha D, Neogi T, Silman AJ, Funovits J, Felson DT, Bingham CO, et al. 2010 Rheumatoid arthritis classification criteria: an American College of Rheumatology/European League Against Rheumatism collaborative initiative. Arthritis Rheum 2010;62:2569-81.

13. Wolfe F, Clauw DJ, Fitzcharles MA, Goldenberg DL, Katz RS, Mease P, et al. The American College of Rheumatology preliminary diagnostic criteria for fibromyalgia and measurement of symptom severity. Arthritis Care Res (Hoboken) 2010;62:600-10.

14. Altman R, Alarcón G, Appelrouth D, Bloch D, Borenstein D, Brandt $\mathrm{K}$, et al. The American College of Rheumatology criteria for the classification and reporting of osteoarthritis of the hand. Arthritis Rheum 1990;33:1601-10.

15. Waddell G, Newton M, Henderson I, Somerville D, Main CJ. A Fear-Avoidance Beliefs Questionnaire (FABQ) and the role of fear-avoidance beliefs in chronic low back pain and disability. Pain 1993;52:157-68.

16. Lundberg M, Grimby-Ekman A, Verbunt J, Simmonds MJ. Pain-related fear: a critical review of the related measures. Pain Res Treat 2011;2011:494196.

17. Altman R, Alarcón G, Appelrouth D, Bloch D, Borenstein D, Brandt K, et al. The American College of Rheumatology criteria for the classification and reporting of osteoarthritis of the hand. Arthritis Rheum 1990;33:1601-10.

18. Korkmaz N, Akinci A, Yörükan S, Sürücü HS, Saraçbaşi O, Ozçakar L. Validation and reliability of the Turkish version of the fear avoidance beliefs questionnaire in patients with low back pain. Eur J Phys Rehabil Med 2009;45:527-35.

19. Demmelmaier I, Bergman P, Nordgren B, Jensen I, Opava $\mathrm{CH}$. Current and maintained health-enhancing physical activity in rheumatoid arthritis: a crosssectional study. Arthritis Care Res (Hoboken) 2013;65:1166-76.

20. Prevoo ML, van 't Hof MA, Kuper $\mathrm{HH}$, van Leeuwen MA, van de Putte LB, van Riel PL. Modified disease activity scores that include twenty-eight-joint counts. Development and validation in a prospective longitudinal study of patients with rheumatoid arthritis. Arthritis Rheum 1995;38:44-8.

21. Felson DT, Smolen JS, Wells G, Zhang B, van Tuyl LH, Funovits J, et al. American College of Rheumatology/ European League Against Rheumatism provisional definition of remission in rheumatoid arthritis for clinical trials. Arthritis Rheum 2011;63:573-86.

22. Singh JA, Saag KG, Bridges SL Jr, Akl EA, Bannuru RR, Sullivan MC, et al. 2015 American College of Rheumatology Guideline for the Treatment of Rheumatoid Arthritis. Arthritis Rheumatol 2016;68:1-26.

23. Labor USDo, Dictionary of Occupational Titles: Volume 1 and Volume $2\left(\mathrm{O}^{*}\right.$ Net Companion to Occupational Outlook Handbook With Detailed Data Summaries). 4th ed. Montreal Way: Jist Works Inc.; 1999.

24. Scott DL, Wolfe F, Huizinga TW. Rheumatoid arthritis. Lancet 2010;376:1094-108.

25. Palstam A, Larsson A, Bjersing J, Löfgren M, Ernberg $\mathrm{M}$, Bileviciute-Ljungar I, et al. Perceived exertion at work in women with fibromyalgia: explanatory factors and comparison with healthy women. J Rehabil Med 2014;46:773-80.

26. Palstam A, Larsson A, Löfgren M, Ernberg M, Bjersing J, Bileviciute-Ljungar I, et al. Decrease of fear avoidance beliefs following person-centered progressive resistance exercise contributes to reduced pain disability in women with fibromyalgia: secondary exploratory analyses from a randomized controlled trial. Arthritis Res Ther 2016;18:116.

27. Bunzli S, Smith A, Schütze R, O'Sullivan P. Beliefs underlying pain-related fear and how they evolve: a qualitative investigation in people with chronic back pain and high pain-related fear. BMJ Open 2015;5:008847.

28. Olofsson T, Johansson K, Eriksson JK, van Vollenhoven R, Miller H, Petersson IF, et al. Does disease activity at start of biologic therapy influence work-loss in RA patients. Rheumatology (Oxford) 2016;55:729-34.

29. Smolen JS. Treat-to-target as an approach in inflammatory arthritis. Curr Opin Rheumatol 2016;28:297-302.

30. Fletcher C, Bradnam L, Barr C. The relationship between knowledge of pain neurophysiology and fear avoidance in people with chronic pain: A point in time, observational study. Physiother Theory Pract 2016;32:271-6.

31. Cosio D, Lin EH. Effects of a pain education program for veterans with chronic, noncancer pain: a pilot study. J Pain Palliat Care Pharmacother 2013;27:340-9.

32. McInnes IB, Combe B, Burmester G. Understanding the patient perspective - results of the Rheumatoid Arthritis: Insights, Strategies \& Expectations (RAISE) patient needs survey. Clin Exp Rheumatol 2013;31:350-7.

33. Strand V, Wright GC, Bergman MJ, Tambiah J, Taylor PC. Patient Expectations and Perceptions of Goal-setting Strategies for Disease Management in Rheumatoid Arthritis. J Rheumatol 2015;42:2046-54. 